\title{
Problemas éticos vivenciados por dentistas: dialogando com a bioética para ampliar o olhar sobre o cotidiano da prática profissional
}

\author{
Ethical problems experienced by dentists: dealing with bioethics \\ to wide the view on the daily professional practice
}

Adriana Gomes Amorim ${ }^{1}$

Elizabethe Cristina Fagundes de Souza ${ }^{2}$

${ }^{1}$ Curso de Odontologia Universidade do Estado do Rio Grandedo N orte. Rua AndréSales 667,

Paulo VI. 59300-000 Caicó RN.Adrianagamorim1@ hotmail.com.

2 Programa de Pós-

Graduação em Odontologia,

UniversidadeFederal do Rio

Grandedo Norte.
Abstract Bioethics strives for humanization in health services along with promoting the rights of patients. In view of the lack of dental research dealing with this topic, the present study was undertaken to identify, from the viewpoint of dental surgeons, ethical problems experienced in dental practice. It is a descriptive exploratory investigation within a qualitative approach. Empirical material was collected through semi-structured interviews performed with 15 dental surgeons in the state of Rio Grande do N orte, Brazil. Theresultsindicatethat many of the ethical problems coincide with infringements of the norms and rules of the Dental Code of Ethics, confirming a dental ethic acquired during professional formation and therefore, inadequate for solving the problems that emerge in professional practice. We concluded that the ethical problemsidentified in professional practice need to be understood beyond the dental dimension, towards a human approach. It is ther efore necessary to incorporate health care management technologies into health practices which imply recognizing the different dimensions that surround individuals and their health needs.

Key words Bioethics, Dentistry, Professional practice, Professional formation
Resumo A bioética busca a humanização dos serviços de saúde ea promoção dos direitos dos usuários. $\mathrm{Na}$ odontologia, são poucos os estudos que tratam dessa temática, o que justificou a realização da pesquisa que apresentamos neste artigo. 0 objetivo do estudo foi identificar, a partir da visão dos cirurgi ões-dentistas, os problemas éticos vivenciados na prática odontológica. Trata-se de uma investigação qualitativa de caráter exploratório descritivo. 0 material empírico foi coletado através de entrevistas semiestruturadas, realizadas com quinze cirurgiões- dentistas que atuam no estado do Rio Grandedo N orte. Os resultadosapontam que muitos dos problemas éticos coincidem com infrações ao Código de Ética Odontológica, confirmando uma noção de ética deontológica adquirida na formação profissional e, portanto, insuficiente para solucionar os problemas que emergem na prática profissional. Concluímos que os problemas éticos identificados na prática profissional precisam ser compreendi dos para além da dimensão deontológica em direção aos aspectos da produção do trabalho. Torna-se preciso, então, incorporar nas práticas de saúde, incluindo as de saúde bucal, as tecnologias da gestão do cuidado, 0 que implica o reconhecimento de diferentes dimensões que produzem os sujeitos e suas necessidadesdesaúde.

Palavras-chave Bioética, Odontologia prática profissional, Formação odontológica 
Introdução

Problemas éticos na prática odontológica ocorrem rotineiramenteepodem envolver aspectos referentes ao paciente, à organização dos serviços de saúde, ao relacionamento com os colegas e com a sociedade como um todo. No entanto, os profissionais nem sempre estão preparados para lidar com as questões de caráter ético, o que pode levá-los a vivenciar conflitos éticos no exercício profissional. Para os dentistas, em especial, as dificuldades na resolução de tais conflitos são reforçadas pela excessiva tecnificação do trabalho odontológico.

Essetecnicismo émantido principalmentepelo ensino odontológico que desconsidera, na maioria das vezes, a produção histórica de saberes e práticas de saúde, ou seja, as dimensões éticopolítica, social ecultural queestão implicadasnas questões da saúde como um todo e, em particular, na prática odontológicaํ.

0 conhecimento odontológico fragmentado em disciplinas - as especialidades técnicas, em sua maioria - dificulta a percepção da integralidade do ser humano, que sempre será a um só tempo biológico, psicológico, cultural esocial. Consequentemente, predomina um modelo dentista-centrado, ou seja, uma clínica baseada na técnica cirúrgica e em procedimentos reparadores do dente ${ }^{2}$.

Outra característica da odontologia é a ênfase dada ao seu caráter privado. Regida pelas leis do mercado capitalista, a prática odontológica tem concentrado a oferta de serviços junto a grupos de média e alta renda, tendo como um dos seus efeitos mais notórios a limitação do alcance social dos avanços tecnológicos ${ }^{3}$. Além disto, a al ocação edistribuiçã̃o de recursos em saúde bucal no setor público têm se dado, ao longo dos anos, deformainsuficientee ineficiente, restando para a grandemaioria da população assistência odontológica inadequada, com enfoque predominantemente cirúrgico-mutilador.

A dicotomia entre prática técnica e prática social é reforçada pela atual situação do mercado odontológico no Brasil, onde a cada ano são formados 11 mil profissionais num contingente de cerca de 155 mil cirurgiões-dentistas4. Diantedesses dados, Vasconcellos ${ }^{5}$ identifica uma crise de real ização de oferta de serviços odontológicos em que, gradativamente, dá-se a substituição do trabalho autônomo pelo assalariado de forma direta (contratação) e indireta (credenciamento). 0 excesso de profissionais concentrados nas grandes cidades também leva a uma concorrência de senfreada e, na briga por pacientes, a dimensão ética da prática profissional é desconsiderada.
Os problemas éticos enfrentados pelos cirurgiões-dentistas são produzidos nas circunstâncias discutidas acima, mas certamente envolvem outras situações. N este artigo, trazemos algumas reflexões, à luz da bioética, a partir de estudo que realizamos com o objetivo de identificar e analisar os problemas éticos vivenciados pelos odontólogos na prática profissional. Esperamos, desta forma, contribuir para a divulgação einclusão do tema da ética na odontologia, ampliando concepções restritas à dimensão deontológica para aspectos da produção de trabalho em saúde bucal e dialogando com outras áreas do conhecimento.

\section{Metodologia}

Trata-se de uma pesquisa de caráter exploratório descritivo, dentro de uma abordagem qualitativa. Os sujeitos da pesquisa foram dentistas que atuam no Estado do Rio Grande do Norte, escolhidos intencionalmente e por adesão: profissionais que trabalham em consultórios particulares, em posto de saúde e como empregados em clínicas populares ou naquelas mantidas por planos odontológicos, tanto na capital quanto no interior do estado. Visamos, dessa forma, identificar os problemas éticos em todas as dimensões do trabalho odontológico. Considerando que os problemas éticos podem surgir logo no início do exercício profissional, escolhemos desde recém-formados até profissionais com trinta anos de experiência. A origem institucional de formação desses profissionais não foi considerada. 0 número de participantes foi definido no decorrer da realização da pesquisa, levando-se em conta 0 alcance dos objetivos propostos pela saturação do conteúdo das entrevistas. 0 total de entrevistados foi de quinze dentistas.

Como critério deexclusão, estabelecemos não incluir os profissionais que estivessem sem exercer atividadeclínica, no último ano, como os desempregados ou os que atuam em atividades, exclusivamente, administrativas ou de ensino.

A pós explicar o propósito e a importância do estudo, os encontros foram marcados com cada entrevistado de acordo com a disponibilidade e local de sua preferência, assegurando-Ihes a confidencialidadena coleta das informações e o anonimato na apresentação dos resultados. Seus nomes foram substituídos por nomes de flores.

Utilizamos um roteiro de entrevista semiestruturado. Este roteiro foi flexível, ou seja, permitiu acomodar qual quer aspecto novo que pudesse emergir ou ser trazido pelo entrevistado ${ }^{6}$. 
As entrevistas foram gravadas e, posteriormente, transcritas naíntegra. As informações trocadas ao final dos encontros e as impressões iniciais da pesquisadora também foram anotadas, logo após o término de cada entrevista ${ }^{6}$. A penas uma das entrevistas deixou de ser gravada, por solicitação da pessoa entrevistada; as informações foram anotadas, buscando-se reproduzir o relato, da forma mais fiel possível.

N esta investigação, garantimos também o esclarecimento, a livre participação e o direito do entrevistado retirar-se da pesquisa em qualquer momento, conforme o termo de consentimento livree esclarecido elaborado segundo a Resolução n 196/96 do Conselho N acional deSaúde ${ }^{7}$ eaprovado pelo comitê de ética em pesquisa da UFRN

$\mathrm{Na}$ análise do conteúdo das entrevistas e das anotações, procuramosidentificar sentidosecompreendêlos, pois o queéreal mentefalado constitui os dados, mas a análise do material, como nos lembra Bauer eGaskell ${ }^{6}$, deveir além da aceitação deste valor aparente. Para esses autores, a entre vista semiestruturada é em si mesma uma tentativa de colocar em termos concretos a idéia de triangulação interna ao método, através da combinação de diferentes enfoques (do tipo narrativo e argumentativo) com respeito ao tema em estudo, a fim deaumentar a qualidade dos dados, das interpretações e dos resultados. No entanto, consideramos importante buscar a triangulação da análise dos dados extraídos do conteúdo das entrevistas, das anotações da pesquisadora e do re ferencial teórico estudado; este, a partir da utilização dediferentes perspectivas da bioética edo contexto de trabalho em saúde bucal ${ }^{8}$.

\section{Resultadosediscussão}

A partir da leitura sistemática do conteúdo das entrevistas, buscamos identificar os problemas éticos contidos nos relatos dos cirurgiões-dentistas. Os problemas identificados no material examinado foram agrupados segundo três dimensões desituações vivenciadas na prática odontológica: problemaséticosidentificados na prática dos colegas ( Q uadro 1); problemas éticosidentificados nas relações com os usuários ( Quadro 2); problemas éticos identificados nas relações de trabal ho e nos serviços de saúde (Quadro 3). A despeito da categorização realizada, os problemas éticos entresi não são indissociáveisuns dos outrose, no decorrer do texto, também se entrelaçam e se superpõem.
Problemaséticos identificados nas práticas dos colegas

Evidenciamos que os conflitos éticos referidos pelos dentistas entrevistados são, em sua maioria, situações nas quais há divergência de pensamentos e atitudes em relação aos colegas de profissão.

Após a análise dos relatos, identificamos de imediato que as situações descritas coincidem com o desrespeito às normas contidas no Código de Ética O dontológica, caracterizando o predomínio da noção de ética vinculada a uma concepção deontológica.

A título de ilustração, selecionamos alguns trechos dos relatos e os associamos a trechos do Código de Ética O dontológica, apresentados no Quadro 4.

Quadro 1. Problemas éticos identificados na prática dos colegas.
- Aliciamento de pacientes.
- Capacitação técnica-científica inadequada ao exercício da atividade.
- Realização de tratamentos desnecessários.
- Comentários desfavoráveis sobre o trabalho realizado por outros colegas.
- Negligência no cuidado com o paciente. - O missão de informações técnicas necessárias à decisão.
- Falta de visão integral do usuário.

Quadro 2. Problemas éticos identificados nas relações com os usuários.

- Desacordo com as escolhas de tratamento dos usuários.

- Identificar e manter-se em silêncio diante de iatrogenias realizadas pelos colegas.

Quadro 3. Problemas éticos identificados nas relações de trabalho e com os serviços de saúde.

- Submissão a condições inadequadas de trabalho. - N ão poder encaminhar o usuário a serviço de referência especializado.

- Número elevado de pacientes associado ao tempo reduzido de atendimento.

- Desvalorização das ações preventivas e educativas.

- Concorrência profissional pelo mercado de trabalho. 
Quadro 4. Comparação entre o Código de Ética O dontológico e alguns problemas éticos relatados pelos dentistas entrevistados.

\begin{tabular}{|c|c|}
\hline Conteúdo do código de ética & Relatos de alguns entrevistados \\
\hline $\begin{array}{l}\text { Capítulo III, art. 5, inciso III: Constituem deveres } \\
\text { fundamentais dos profissionais manter } \\
\text { atualizados os conhecimentos profissionais, } \\
\text { técnico-científicos e culturais, necessários ao } \\
\text { pleno desempenho do exercício profissional. }\end{array}$ & $\begin{array}{l}\text { Quando eu cheguei lá vi que tinha um kit de } \\
\text { resina foto completo. Aí, eu disse: que legal! Você } \\
\text { tem resina fotopolimerizável. Aí, ele: "não minha } \\
\text { filha, isso não é resina, não. É material para } \\
\text { obturar canal". Ele nem sabia que aquilo era } \\
\text { resina! (Gardênia) }\end{array}$ \\
\hline $\begin{array}{l}\text { Capítulo V, seção I, art. 7, inciso III: Constitui } \\
\text { infração ética exagerar em diagnóstico, } \\
\text { prognóstico ou terapêutica. }\end{array}$ & $\begin{array}{l}\text { Já vi profissional dizer: "se a pessoa vem para mim } \\
\text { com o primeiro molar e no segundo molar a } \\
\text { restauração é profunda, eu digo logo para fazer o } \\
\text { canal. Vamos fazer os dois por que mais cedo ou } \\
\text { mais tarde vai precisar". (Lírio) }\end{array}$ \\
\hline $\begin{array}{l}\text { Capítulo V, seção II, art. 9, inciso I: Constitui } \\
\text { infração ética desviar paciente de colega. }\end{array}$ & $\begin{array}{l}\text { O profissional quer roubar o paciente do outro. A } \\
\text { filosofia predominante é: "melhor perder o amigo } \\
\text { do que o paciente". (Tulipa) }\end{array}$ \\
\hline
\end{tabular}

A noção deontológica predominante nas falas dos entrevistados justifica-se na medida em que o ensino da ética nos cursos da área de saúde e, particularmente, na odontologia, épautado na transmissão de regras estabelecidas como direitos e deveres reunidos em códigos de ética profissional $^{9}$. No entanto, a perspectiva de tais regras evalores deontológicos élimitada diantedos problemas e/ ou dilemas éticosvivenciadosno cotidiano pelos profissionais.

A consequência da formação alicerçada em normas deontológicas, e de caráter comportamental, é a carência no que diz respeito a uma fundamentação crítica e reflexiva. 0 saber profissional é dirigido a uma objetividade tecnicista e com ênfase no aparato tecnológico, que em grande medida desconsidera as subjetividades dos termos intervenientes sobre seus cuidados ${ }^{9}$.

N esse sentido, M orin ${ }^{10}$ nos inspira a afirmar que o conceito de ética no cotidiano do ensino odontológico precisa também ser ampliado de uma ética profissional, codificada em obrigações e direitos, para uma ética do gênero humano, visando a aprender um saber-ser e não somente um saber-fazer. Para o autor, alcançar esta ética implica quea educação assuma a concepção complexa do humano, comportando a tríade indivíduo/sociedade/espécie ${ }^{10}$.

Contudo, a formação tradicional em saúde, baseada na organização disciplinar e nas especialidades, conduz ao estudo fragmentado dos problemas de saúde das pessoas e das socieda- des, levando à formação de especialistas que não conseguem mais lidar com as totalidades ou com realidades complexas. Formam-se profissionais que dominam diversos tipos de tecnologias, mas tornam-se cada vez mais incapazes de lidar com a subjetividade e a diversidade moral, social e cultural das pessoas ${ }^{11}$.

A formação odontológica é, em parte, responsável pela manutenção de uma prática centrada na assistência individual, realizada com exclusividade por um sujeito individual, o cirurgião-dentista, no restrito ambiente clínico. Esta concepção tem forte influência no desenvolvimento da ciência e da tecnologia odontológica ${ }^{12}$.

As técnicas e tecnologias odontológicas são os saberes e as práticas que tomaram como seu objeto os dentes e, eventualmente, a boca ${ }^{13}$, promovendo o desenvolvimento de materiais e procedimentos cirúrgico-restauradores a partir de um saber organizado no interior das disciplinas odontológicas: cirurgia, dentística, periodontia, endodontia, ortodontia, materiais dentários. Segundo Botazzo ${ }^{14}$, "os dentes vincam de tal modo o espaço de um saber, ea tal ponto, que continuam como referentes até mesmo quando estão ausentes por completo do seu cenário de emergência", aqui se referindo à prótese.

0 termo tecnologia não engloba apenas 0 conjunto de máquinas, equipamentos e instrumentos odontológicos. Há outras formas de tecnologia representadas pelo saber científico (esua aplicação/utilização pelos profissionais), pela 
organização da prestação dos serviços e pelas formas de aproximação com os usuários. M erhy ${ }^{15}$ discute o trabalho em saúde e as tecnologias utilizadas classificando-as em duras (ferramentas e equipamentos), leve-duras (saberes estruturados) eleves (saberes adquiridos no processo de trabal ho "em ato").

A tecnologia "leve", entendida como o processo de relações entre o trabalhador de saúde e 0 usuário ${ }^{3,15}$ de expressar-se na gestão do cuidado, traz consigo a proposta de humanização do processo de desenvolver ações e serviços de saúde. A humanização, vista como prática inerente ao trabalho em saúde, implica a responsabilização dos serviços e dos trabalhadores da saúde, em construir, com os usuários, a resposta possível às suas dores, angústias, problemas e aflições ${ }^{16}$.

0 mercado, por outro lado, tem influenciado a ênfase em programas que incorporam tecnologias "duras", ou seja, em modelos de práticas estruturadas a partir de aparato tecnológico de densidade e custo elevados, e de difícil acesso para 0 usuário. Este modelo requer profissionais cada vez mais especializados e pouco qualificados para perceber eatuar em dimensões mais amplas do processo saúde-doença ${ }^{3}$, ou seja, com baixa capacidade técnica para desenvolver tecnologias leves e leves-duras.

0 cuidado com o ser humano é negligenciado ao invés de ser o centro das ações. A escola, além de educar para a inteligência e a razão, deveria também educar para a cidadania e a emoção. Da mesma forma que o aluno precisa ser preparado para realizar as técnicas, também deve ser preparado para lidar com pessoas, levando em consideração sentimentos, o ser completo de um indivíduo?.

As discussões interdisciplinares promovidas pela bioética podem servir como base de mudança no processo de ensino-aprendizagem da ética nos cursos de ciências de saúde. 0 seu enfoque deve contemplar principalmente os princípios da autonomia dos diversos atores sociais, a pluralidade sociocultural das pessoas, a definição dos conteúdos tendo como referência a responsabilidadecientífica esocial das áreas de saúde. Aos três pontosacima referidos, devem ser agregados, ainda, os princípios da beneficência, da justiça, da excelência (qualidade) e da virtude ${ }^{17}$.

Em conformidade com Germano ${ }^{18}$, o fundamental é estruturar o ensino de ética a partir da compreensão da realidade social e do exercício da crítica sistemática às questões mais gerais da saúde eda sociedade que repercutem no dia a dia da profissão e na assistência que dispensamos aos usuários. Sem essa visão, partimos para um discurso ético-filosófico na sala de aula, totalmente vazio, e desvinculado da real idade social.

A formação ética do profissional de saúde deve ser iniciada no ciclo básico da formação de nível superior, enfatizando a análise dos problemas e casos práticos que poderão acontecer na realidade concreta da vida profissional de futuros dentistas ${ }^{19}$.

Nesta perspectiva, torna-se importante que essas discussões não fiquem restritas ao âmbito acadêmico. Os profissionais devem ser continuamente preparados para a superação de suas limitações e para aperfeiçoamento eatual ização técnicos, a partir da educação permanente, poiso compromisso ético dos profissionais pode ser desenvolvido em qualquer etapa da vida humana ${ }^{20}$

Consideramos, pois, que formar profissionais éticos ecidadãos responsáveis por suas ações é um grande desafio para o ensino; isto é, dotar profissionais de visão crítica da realidade e com competência para agir de forma responsável, autônoma e, fundamentalmente, comprometidos com os usuários, a comunidade e seu trabalho.

\section{Problemas éticos identificados nas relações com os usuários}

A ética médica foi desenvolvida a partir dos trabalhos de Hipócrates. A atitude do médico perante o paciente, desde então, baseava-se no modelo da beneficência e cabia unicamente ao médico a decisão, tanto diagnóstica quanto terapêutica, ao passo que a obrigação do doente era acatar passivamente as decisões e prescrições ${ }^{21}$. A beneficência éo princípio por meio do qual o profissional deve ter em mente que todo ato ou ação deve, obrigatoriamente, trazer benefícios ao paciente ${ }^{22}$.

A partir da definição dos direitos humanose do desenvolvimento da democracia e da cidadania, iniciam-se os debates a respeito da necessidade de se destacar a posição do paciente e de se valorizar ainda mais sua responsabilidade com o tratamento.

O usuário passa a ser visto como um agente autônomo, ou seja, respeitado no seu direito de ter opiniões próprias, fazer escolhas eagir deacordo com seus valores e crenças, lembrando que, muitas vezes, suas opções podem discordar das indicações técnicas. A posição do usuário não podeser a de um objeto que recebeum benefício, mas a de um sujeito que discute opiniões sobre sua saúde, seu tratamento e seu bem-estar. A 
concretização dessa autonomia se daria através da obtenção do consentimento livre e esclareci$\mathrm{do}^{23}$. No entanto, sabemos que a autonomia não se reduz à formalização de um consentimento, mas implica conquistas de cidadania, isto é, o exercício de direitos sociais, políticos e econômicos que, em nossa realidade brasileira, a maioria da população ainda tem muito a conquistar.

O pleno exercício do consentimento somente é possível após serem discutidos com o usuário pontos essenciais como o diagnóstico, o plano detratamento, as consequências dos procedimentos, incluindo possíveis sequelas, caso existam, e os seus custos. A linguagem precisa ser clara e acessível dentro dos padrões de compreensão intelectual, cultural e psicológica do indivíduo. Para informar o usuário, épreciso, antes detudo, ser capaz de comunicar-se com ele. A comunicação é um dos pilares mais importantes para o alcance do relacionamento efetivo entreo profissional e o usuário e talvez esteja relacionado a uma das grandes barrei ras a serem superadas na odontologia. As habilidades técnicas não suplementam a necessidade de se estabelecer uma re lação com o usuário que propiciesegurança, confiança e comprometimento ${ }^{9}$.

Um de nossos entrevistados corrobora a importância da informação e da interação com o usuário: Acho que o essencial é a informação. Informar o paciente o que ele precisa e o que você é capaz de fazer por aquilo ali. Q ue o paciente participe tanto do seu plano de tratamento quanto da execução, sempre ele decidindo junto com você 0 que deve ser feito. (M argarida)

No presenteestudo, os entrevistados demonstraram preocupação em preservar o direito à autonomia dosusuários, desde que as consequências das decisões não resultassem em ameaças à integridadedosindivíduos. Em taissituações, percebemos quese impõeo princípio da não-maleficência, pois o tratamento só é aceito ou recusado pelo profissional após serem ponderados os custos e ben efícios de sua administração. De acordo com este princípio, o profissional deve, além de beneficiar, não causar danos aos pacientes.

Destacamos ainda que as decisões não envolvem somente aspectos técnicos, mas também os valores, as metas pessoais e as concepções singulares de saúde, felicidade e bem-estar dos usuários dos serviços odontológicos ${ }^{5}$. N esse sentido, concordamos com Garbin et al. ${ }^{24}$ ao afirmar que a percepção do usuário como um todo, com personal idade específica, problemas e anseios particulares, é fundamental para a boa comunicação e o sucesso do atendimento odontológico.
Entretanto, 0 aprendizado acadêmico é direcionado ao domínio do conhecimento técnico através de disciplinas, na maioria, com enfoque dentário, dificultando a compreensão do ser humano como produção biopsicossocial: Eu me encontrei com uma amiga que está fazendo odonto e ela estava super feliz por que tinha feito a primeira extração. "O máximo, né? Ah, eu extrai etal". Mas nem pensava na pessoa que perdeu o dente, né?o que isso podia causar para a pessoa. Não é culpa dela por queela está ali para aprender a fazer aquilo mesmo, mas acho que falta um pouquinho assim [deética] dos professores dealgumas disciplinas, de repente na disciplina de cirurgia, né? Ter alguma coisa em relação a isso para que a pessoa se ache bacana porque fez a técnica correta, mas se sensibilize também com a pessoa que está ali. ( Lírio)

0 modelo de ensino vigente traz as marcas do relatório Flexner proposto em 1910. Este documento é baseado na aplicação de regras cartesianas como norteadoras da formação médica. 0 conhecimento fragmentado passa a ser privilegiado de acordo com as percepções específicas de diferentes áreas do saber médico, desconsiderando-se a inseparabilidade entre as partes e 0 todo do ser humano. 0 indivíduo, antes de ser visto como sujeito de seu processo terapêutico, de ser respeitado em sua dignidade, vontade, liberdade e razão, transforma-se em objeto de estudo, em consumidor de tecnologias 25-27.

Encontramo-nos diante, portanto, de um modelo pedagógico obsoleto.Torna-se urgente, então, a adoção de novas propostas pedagógicas para o ensino que melhor atendam as necessidades do ser humano enfermo. As novas estratégias de ensino a serem incorporadas devem fornecer conhecimentos mais amplos do processo saúde-doença, contemplando enfoque inter etransdisciplinar.

Ainda épertinente considerar que, não obrigatoriamente, o usuário que concorda com indicações do dentista esteja devidamenteesclarecido em um processo de consentimento e, ainda que o estivesse, não se pode desprezar os aspectos relativos ao sistema de saúde e ao acesso aos serviços como potenciais determinantes de restrição da liberdade das pessoas. $\mathrm{Na}$ impossibilidade de acesso ao tratamento endodôntico, como acontece principalmente no sistema público, o usuário consente em extrair dentes, não por que avaliou todas as alternativas e escolheu aquela que mais se adaptava a sua necessidade, mas sim por completa falta de opção. Da mesma forma, há situações, no setor privado, quando o usuário não tem capacidade financeira de consumo das ofertas de mercado. 
Outro problema abordado por nossos entre vistados diz respeito à omissão dos profissionais frente às iatrogenias cometidas pelos colegas.

Detectamos receio por parte dos entrevistados em informar ao usuário que o tratamento realizado pelo colega não foi executado dentro das adequadas normas técnicas. Consideram que, assim, estariam desrespeitando as regras da ética deontológica, representadas pelo Código de Ética O dontológica, que tem influência importante no exercício da profissão. A má conduta profissional é, na maioria das vezes, envolvida por um muro de silêncio, especialmente quando o usuário não está ciente do problema ou, então, se a falha é percebida pela pessoa, a situação é contornada por descul pas quejustifiquem a ação realizada pelo colega, constituindo-se numa certa "leal dade" com os demais dentistas.

No entanto, esse respeito ao código de ética não é absoluto. Diante de iatrogenias sérias que impliquem ameaça à saúde do indivíduo, alguns participantes da pesquisa consideram que deve prevalecer uma postura honesta com os usuários dos serviços odontológicos. Nesses casos, julgam que denunciar o colega torna-se justificável, pois estaria em jogo a integridade de um ser humano.

Problemas éticos identificados nas relações de trabal ho e nos serviços de saúde

A universalidade da cobertura, a igualdade deacesso ea integralidade da assistência são os princípios fundamentais do SUS relacionados ao princípio da justiça. A partir deles, é possível estabelecer as bases de uma gestão moralmente legítima esocialmente aceitável no contexto de saúde brasileiro ${ }^{28}$.

Contudo, ao se considerar que o SUS ainda seencontra em fase deimplementação, apesar de definido legalmentedesdea constituição de 1988, não deve causar estranheza o fato de uma parte dos problemas éticos vividos pelos profissionais de saúde que atuam no serviço público serem decorrentes deaspectos organizacionais do sistema de saúde.

No caso particular da odontologia, muitos problemas éticos relacionam-se com a questão da integralidade no que se refere à hierarquização dos níveis de assistência como, por exemplo, a falta de um serviço de referência especializado, principalmente em endodontia. A ampliação do acesso ao tratamento endodôntico diminuiria, sem dúvidas, o montante de exodontias e de necessidades de tratamento reabilitador que a perda dentária ocasiona.
O usuário, mesmo diante da possibilidade de recuperação do seu quadro clínico pelo conhecimento técnico-científico disponível na odontologia, é obrigado a extrair dentes. Sabemos quea perda dentária ainda é vista com naturalidade em nossa prática, pois o paradigma curativoreabilitador encontra-se profundamente enraizado em nossas ações. 0 ol har profissional é reduzido ao "tratar de dentes", sendo o indivíduo e seu contexto, na maioria das vezes, esquecido no que poderia ser uma ação de cuidado.

Como já discutimos no tópico anterior, essa percepção é reforçada pelo modelo cartesiano de ensino-aprendizagem, a partir do qual as doenças são compreendidas como processos individuais, naturais e biológicos, guardando relações exclusivas com determinados órgãos ${ }^{26}$.

Tais concepções estão, evidentemente, presentes nas formas de organização da assistência. 0 centro da atenção, ao longo da nossa história, tem sido a doença em detrimento do doente. Esta visão norteou a elaboração das políticas públicas no Brasil que se centraram num modelo de assistência hospitalocêntrica, com rápida incorporação de procedimentos de alta densidade tecnológica e pouco investimento em ações preventivas e de promoção da saúde.

A saúde bucal da população, nesse contexto, não foi considerada prioritária e, segundo dados do Instituto Brasileiro de Geografia e Estatística (IBGE), de 1998, até aquele ano, trinta milhões debrasileiros nunca tinham ido ao dentista ${ }^{29}$. Um crescente processo demercantilização foi produzido e a alta tecnologia odontológica tem sido disponibilizada apenas para aqueles que podem pagar pelos seus serviços, o que representa a minoria da população. Para a maior parte da população, são oferecidas exodontias, muitas vezes, como o único recurso terapêutico possível.

Nestes últimos anos, al gumas iniciativas de expansão da cobertura da assistência odontológica, no setor público, têm sido observadas - a inclusão da equipe de Saúde Bucal no Programa Saúde da Família desde 2001, logo após a divulgação dos dados da pesquisa do IBGE ${ }^{30}$, e em 2004, o lançamento do programa Brasil Sorridente ${ }^{16}$, política nacional que incorpora propostas de assistência integral com expansão dos serviços odontológicos desde a atenção básica, pelo incremento do número de equipes de saúde bucal da família, até a implantação de serviços especializados nos demais níveis de atenção. Além do atendimento básico curativo e das ações preventivas e promocionais, o programa incentiva a implantação de centros de especialidades odon- 
tológicas para referência em endodontia, periodontia e prótese ${ }^{16}$.

Problemas relacionados com as ações dos gestores do SU S ao nível municipal da assistência de saúde também foram relatados pelos entrevistados.

A política dedescentralização do SUS exigedos municípios um bom desempenho de sua capacidade de gestão para a implantação de serviços e ações de saúde voltadas para a mudança positiva nos indicadores de saúde da população. $\mathrm{Na}$ condução do processo de atenção à saúde, o gestor municipal tem papel fundamental esuas decisões, por afetarem tanto os indivíduos quanto as coletividades, são atos de natureza ética, devendo ser guiados pelo princípio da responsabilidade.

As transformações das ações de saúde, entretanto, não dependem apenas das atitudes do gestor, mas também do envolvimento e do compromisso dos profissionais, incluídos aí os dentistas. Observamos nos relatos obtidos nesta pesquisa que a preocupação maior dos profissionais direciona-seà estruturação do consultório odontológico: Tem que se impor. N ão tinha nada quando cheguei lá. E eu disse: "eu não trabalho assim, não adianta". Não chega um incentivo do governo? U se aquele dinheiro para comprar material. Então para eu começar a trabalhar, o secretário de saúde teve de comprar o todo o instrumental. Teve que equipar toda a sala para que realmenteaquilo se parecessecom um consultório odontológico. (Gardênia)

Reconhecemos que dispor de condições de trabalho adequadas é importante, mas que outras questões dificultam o processo de trabalho, como a própria adequação da formação do profissional para atuar no SUS.

A formação dos trabalhadores de saúde bucal ainda não seorienta pela compreensão crítica das necessidades sociais de saúde. 0 modelo formador continua dissociado da realidade de saúde da população brasileira. Quanto ao mercado, crescem a competição por postos de trabal ho odontológico e a disputa de profissionais para assegurarem seu emprego, numa população de dentistas que cresce cerca de 5,7\% ao ano, enquanto 0 crescimento anual da população é de $1,6 \%{ }^{26}$. A concorrência no mercado é também uma realidade para os dentistas e tem implicações na dimensão ética da prática profissional. Com exceção de um dos entrevistados, todos consideraram este fato como fator importante na geração dos desrespeitos éticos.

A despeito do alto número de profissionais, a maior parte da população tem baixa capacidade de financiar, com seus próprios recursos, os cuidados de que necessita em clínicas estruturadas dentro do modelo liberal clássico (entendimento direto quanto aos serviços e honorários entre profissional e usuário). Em contrapartida, também há dificuldades deacesso aos serviços públicos, estes sendo ainda considerados de qualidade inferior; e ainda há um número razoável de pessoas que nunca fizeram consulta odontológica, como mostraram os dados da pesquisa do IBGE ${ }^{29}$ (que $18,7 \%$ da população brasileira nunca foi ao dentista). Estes fatos apontam para a necessidade de se organizar o setor de forma a prover a assistência odontológica aos milhões de pessoas que dela necessitam e, ao mesmo tempo, absorver a abundância de profissionais no mercado de trabalho' ${ }^{29}$.

A dificuldade de inserção no mercado de trabalho tem levado os profissionais a buscar a contratação direta em clínicas odontológicas, onde muitas vezes são oferecidos baixos salários, recursos técnicos precários e, sobretudo, uma demanda sufocante. Contudo, tais condições também são encontradas em alguns serviços do setor público.

Os entrevistados nesta pesquisa acreditam que a busca por uma melhor remuneração tem levado alguns profissionais a realizarem procedimentos para os quais não possuem a devida capacitação técnico-científica, tendo sido citadosos tratamentosendodônticos, protéticose, principalmente, os ortodônticos, por serem aqueles que proporcionam os maiores ganhos ao profissional. A respeito dos males produzidos, observe o relato a seguir: Eu vi profissional dizendo ao paciente que estava fazendo canal quando não estava fazendo canal nenhum. Q uando ele só abria o dente mal e colocava um conesolto dentro deum dente, fechava e pronto. Estava feito o canal. (Azaléia)

0 que pode estar implícito nestas ações éfalta decompromisso ederesponsabilidade do profissional com o usuário, resultando em um alto número de iatrogenias, o que vai de encontro ao princípio da não-maleficência, isto é, a obrigação de não prejudicar e de não impor riscos de danos, intencionalmente, ao usuário.

0 fundamento ético que devenortear as práticas de saúde é a promoção do bem-estar dos indivíduos, o restabelecimento da saúdeintegral. A beneficência, então, é uma exigência para as profissões de saúde, incluindo a odontologia, na medida em que é um princípio que guia a agir segundo o melhor interesse do outro.

A efetivação da beneficência se expressa em compromissos e responsabilidades dos profissio- 
nais não apenas em nível individual, mas também coletivo. A promoção de saúde e bem-estar da população deveser o objetivo, o fundamento e a justificação das profissões de saúde ${ }^{12}$.

Para sermos capazes de promover o bemestar, precisamos ol har o usuário de modo integral. Portanto, a relação sujeito-objeto, hegemônica na prática odontológica, precisa ser substituída pela relação sujeito-sujeito. 0 usuário não deve mais ser visto como uma boca ou como um dente, objeto do desenvolvimento das técnicas cirúrgico-reabilitadoras. Devemos ampliar nossa visão de uma clínica dente-centrada em dire ção a uma saúde bucal integral, tanto na formação quanto no trabalho odontológico.

Encontramo-nos, portanto, diante da necessidade de mudanças não somente dos antigos paradigmas técnico-científicos, como também dos compromissos e responsabilidades profissionais. Será preciso tomar a produção da vida em sua dimensão complexa erelacional, como princípio e desafio do agir ético, para que então possamos reconhecer, compreender e lidar com os problemas/dilemas éticos que surgem no cotidiano, em especial, na prática profissional.

\section{Consideraçõesfinais}

Os problemas éticos apontados referem-se, principalmente, ao desrespeito às normas e regras do Código de Ética Odontológica, confirmando a primazia do enfoque deontológico no ensino da ética durante a formação profissional. No entanto, o conhecimento dos deveres e direitos profissionais é insuficiente para solucionar os conflitos éticos queemergem no exercício da profissão, pois oferece uma visão muito restrita dos problemas.

Dessa forma, a formação ética do profissional não possibilita reflexões críticas de suas práti- cas e é reforçada, também, por formas fragmentadas de conhecimento, com ênfase no tecnicismo, no aprendizado das técnicas cirúrgico-restauradoras que tomam como objeto os dentes, distanciando-se da compreensão mais ampliada do processo saúde-doença. Por outro lado, as ações são desenvolvidas na direção de curar a doença deum indivíduo, negligenciando o cuidado da pessoa doente e a perspectiva de contribuir para que o doente desenvolva maiores níveis de autonomia e autocuidado. Falta ao profissional, durante sua formação e nos espaços de trabalho, a reflexão crítica, por exemplo, sobre a prática odontológica apresentar baixa resolutividade aos problemas básicos da população, como a cárie e a doença periodontal, queainda persistem em elevados níveis na população adulta.

Tais limites colocam para a odontologia a necessidade de nova prática que considere a humanização, o cuidado, o exercício da cidadania e a compreensão de que as condições de vida têm papel fundamental na definição do processo saúde-doença das populações, demandando dos dentistas novas habilidades para lidar com a realidade social, visando alcançar a integralidade das ações de saúdebucal. Faz-seimportante, pois, incorporar no cotidiano do trabalho, no setor saúde, processos educativos que permitam a organização das práticas profissionais a partir das necessi dades de saúde da população. A educação deverá ser enfatizada como instrumento formador de um sujeito socialmente responsável e como elemento fundamental no contexto da atenção à saúde.

O modelo hegemônico de prática odontológica baseado na clínica dente-centrada deve ser substituído, então, pelo "cuidado em saúde bucal" ${ }^{31}$, do qual deriva uma nova prática mais conectada com as dimensões da subjetividade humana.

\section{Colaboradores}

AG Amorim elaborou a pesquisa e escreveu 0 manuscrito e ECF Souza orientou a execução do trabalho. 
1. Amorim KPC. Nos labirintos da vida: a (bio)ética na formação de odontólogos (a visão de docentes) [dissertação]. Natal (RN): Universidade Federal do Rio Grande do Norte; 2002.

2. Souza ECF. Formação e trabalho em odontologia: ampliar a clínica para construir uma nova cultura de cuidado em saúde bucal. [site da Internet] [acessado 2006 out 16]. Disponível em: http:// www.observatorionesc.ufrnet.br

3. Pinto VG. Saúde bucal coletiva. São Paulo: Editora Santos; 2000.

4. Queluz DP. Recursos humanos na área odontológica. In: Pereira AC, organizador. Odontologia em saúde coletiva: planejando ações e promovendo saúde. Porto Alegre: Artmed; 2003. p.140-157.

5. Vasconcellos IC. Ética para a Odontologia. RBO 2003; 60(2):78-79.

6. Bauer MW, Gaskell G. Pesquisa qualitativa com texto, imagem e som: um manual prático. Petrópolis: Vozes; 2002.

7. Brasil. Conselho Nacional de Saúde. Diretrizes e normas regulamentadoras de pesquisa envolvendo seres humanos. [site da Internet]. 1997 [acessado 2006 nov 12]. Disponível em: http:// conselho.saude.gov.br/docs/Reso196.doc

8. Triviños ANS. Introdução à pesquisa em ciências sociais: a pesquisa qualitativa em educação. São Paulo: Atlas; 1987.

9. Creutzberg $M$, Funck $L$, Kruse $M H L, M$ ancia JR, organizadores. A construção do compromisso ético na formação dos acadêmicos do curso de Enfermagem da Universidade Federal de Santa M aria UFSM . In: Livro-Temas do $56^{\circ}$ Congresso Brasileiro de Enfermagem; 2004 Out 24-29; Gramado, Brasil. Brasília: ABEn; 2005.

10. Morin $E$. Os setes saberes necessários à educação do futuro. São Paulo: Cortez; Braślia: UNESCO, 2002.

11. Ceccim R. Mudança na graduação das profissões de saúde sob o eixo da integralidade. Cad Saude Publica 2004; 20(5):1400-1410

12. Frazão P. Tecnologias em saúde bucal coletiva In: Botazzo C, Freitas SFT, organizadores. Ciências sociais e saúde bucal: questões e perspectivas. São Paulo: EDUSC/UNESP; 1998. p. 159-174.

13. N ovaes HMD. Tecnologia e saúde: a construção social da prática odontológica. In: Botazzo C, Freitas SFT. Ciências sociais e saúde bucal: questões e perspectivas. São Paulo: EDUSC/UNESP; 1998. p. 141-173.

14. Botazzo C. Da arte dentária. São Paulo: Hucitec; 2000.

15. Merhy EE. Em busca do tempo perdido: A micropolítica do trabalho vivo em saúde. In: M erhy $E E$, Onocko R, organizadores. Agir em saúde: um desafio para o público. São Paulo: Hucitec; 1997. p. 71-112.
16. Brasil. M inistério da Saúde. Diretrizes da Política Nacional de Saúde Bucal. [site da Internet]. 2004 [acessado 2006 jul 05 ]. Disponível em: http://www. saude.gov.br

17. Garrafa V. A dimensão da ética em saúde pública. São Paulo: Faculdade de Saúde Pública; 1995.

18. Germano RM. A Evolução do Ensino da Ética para Enfermeiros. [site da Internet] [acessado $2006 \mathrm{abr}$ 18]. Disponível em: http:// www.portalmedico.org.br

19. Gomes JCM. O Atual Ensino da Ética para os Profissionais de Saúde e seus Reflexos no Cotidiano do Povo Brasileiro. Rev Bioética 1996; 4(1):39-45.

20. Durand G. Introdução geral a bioética. São Paulo: Loyola; 2003.

21. Almeida JLT. Respeito à autonomia do paciente e consentimento livre e Esclarecido: uma abordagem principialista da relação médico-paciente [tese]. Rio de Janeiro (RJ): Escola Nacional de Saúde Pública; 1999.

22. Garrafa V. Bioética e odontologia. In: Kriger L, organizador. Promoção de saúde bucal. São Paulo: Artes M édicas; 1997. p. 465-475.

23. Zoboli ELCP, M assarollo MCKB. Bioética e consentimento: uma reflexão para a prática de enfermagem. 0 mundo da saúde 2002; 26:65-70.

24. Garbin CAS, Mariano RQ, M achado TP, Garbin AJI. Estudo bioético das relações humanas no tratamento odontológico. Rev Fac O dontol Lins 2002; 14(1):54-59.

25. Camargo MCVZA. 0 ensino da ética médica e o horizonte bioética. Rev Bioética 1996; 4(1):47-51.

26. Siqueira JE. Tecnologia e medicina entre encontros e desencontros. Rev Bioética 2000; 8(1):55-67.

27. Siqueira JE. A arte perdida do cuidar. Rev Bioética 2002; 10(2):89- 106.

28. Kligerman J. Bioética em Saúde Pública. Rev Bras Cancerol 2002; 48(3):305-307.

29. Sória ML, Bordin R, Costa Filho LC. Remuneração dos serviços de saúde bucal: formas e impactos na assistência. Cad Saude Publica 2002; 18(6):1551-1559.

30. Furtado LAC, Tanaka OY. Processo de construção de um distrito de saúde na perspectiva de gestores e médicos: estudo de caso. Rev. Saude Publica 1998; 32(6):587-595.

31. Souza ECF. Bocas, câncer e subjetividades: patografias em análise [tese]. Campinas (SP): Universidade de Campinas; 2003.

Artigo apresentado em 26/03/2007

Aprovado em 31/05/2007

Versão final apresentada em 15/06/2007 